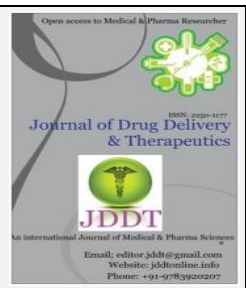

\title{
Analytical Method Development and Validation for Anti Asthamatic Drug Oxymetazoline Hydrochloride in Nasal Spray Formulations by RP-HPLC
}

\author{
Pankaj N. Kulkarni 1, Alaknanda M. Dodake-Supekar,2, A. S. Nipte1 ' C. K. Jadhav' ${ }^{1}$, Charansingh H. Gill1* \\ ${ }^{1}$ Department of Chemistry, Dr. Babasaheb Ambedkar Marathwada University, Aurangabad, Maharashtra, India 431004; \\ 2 Department of Chemistry, S.B.E.S.College of science, Aurangpura, Aurangabad, Maharashtra, India 431001
}

\begin{abstract}
A new, simple, accurate and economic reverse-phase HPLC method has been developed for quantification of Oxymetazoline Hydrochloride in nasal spray formulations. This developed method has been validated according to International Conference on Harmonization (ICH) guideline with respect to system suitability, specificity, precision, linearity, accuracy, and robustness. An isocratic condition of mobile phase Phosphate buffer (pH 3.0): Acetonitrile in a ratio of 60:40, v/v at a flow rate of $1.0 \mathrm{~mL} / \mathrm{minute}$ over RP C18 (octadecylsilane (ODS), $250 \times 4.6 \mathrm{~mm}, 5 \mu \mathrm{m}$, ECLIPSE X DB C-18) column at ambient temperature was maintained. This method is specific and showed excellent linear response with correlation coefficient $\left(\mathrm{R}^{2}\right)$ values of 0.999 , which was within the limit of correlation coefficient $\left(\mathrm{R}^{2} 0.995\right)$. A simple and accurate reversedphase HPLC method for the analysis of Oxymetazoline Hydrochloride in nasal spray formulations was developed and validated successfully.
\end{abstract}

Keywords: Oxymetazoline hydrochloride, ICH, RP-HPLC, Validatation and Nasal Spray.

Article Info: Received 06 July 2019; $\quad$ Review Completed 14 Aug 2019; Accepted 20 Aug 2019; Available online 30 Aug 2019

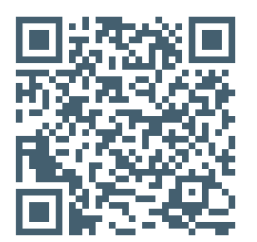

Cite this article as:

Kulkarni PN, Dodake-Supekar AM, Nipte AS, Jadhav CK, Gill CH, Analytical Method Development and Validation for Ant Asthamatic Drug Oxymetazoline Hydrochloride in Nasal Spray Formulations by RP-HPLC, Journal of Drug Delivery and Therapeutics. 2019; 9(4-A):505-510 http://dx.doi.org/10.22270/jddt.v9i4-A.3483

Charansingh H. Gill, Department of Chemistry, Dr. Babasaheb Ambedkar Marathwada University, Aurangabad, Maharashtra, India 431004

\section{INTRODUCTION}

Asthma is a chronic disease that inflames the airways (i.e. the small tubes, called bronchi) which carry air in and out of the lungs. In asthmatic patient, the bronchi will be inflamed and more sensitive than normal and produce extra mucus. This can make breathing difficult due to reversible airflow obstruction, or bronchospasm, and trigger coughing, wheezing and shortness of breath.

The cause of asthma is probably due to a combination of the following factors:

Environmental: allergens (e.g., house dust mites, animal fur and pollen), occupational irritants (e.g. chemical fumes, gases, dust or other substances on the job), tobacco smoke, respiratory (viral) infections, strong emotional expressions and drugs (e.g. aspirin and beta blockers).

Genetic (inherited): usually occurs in children. The chances of developing asthma are increased if the patients' family members or relatives have asthma and other allergic conditions such as atopic dermatitis and hay fever ${ }^{1}$. Hay fever also known as Allergic rhinitis, is a type of inflammation in the nose which occurs when the immune system overreacts to allergens in the air ${ }^{2}$.

Antiasthmatic drugs are used for the treatment of asthma. They may be useful either in the treatment or prevention of asthma attacks ${ }^{3}$. Asthma and allergic rhinitis are related health conditions. Effective treatment for allergic rhinitis may reduce the chance of severe asthma attacks, and make the lungs work better ${ }^{4}$. People those having both asthma and allergic rhinitis should use both a preventer nasal spray and an asthma preventer inhaler regularly. The addition of Oxymetazoline adds to the effectiveness of Fluticasone furoate in the treatment of perennial allergic rhinitis 5 .

Oxymetazoline is available over-the-counter as a topical decongestant in the form of Oxymetazoline hydrochloride in nasal sprays such as Otrivin, Afrin, Operil, Dristan, Dimetapp, Oxyspray, Facimin, Nasivin, Nostrilla.It is used to relieve nasal discomfort caused by colds, allergies, and hay fever6.

Its molecular formula is $\mathrm{C}_{16} \mathrm{H}_{24} \mathrm{~N}_{2} \mathrm{O} \bullet \mathrm{HCl}$ with the following chemical structure: 
<smiles>Cc1cc(C(C)(C)C)c(O)c(C)c1CC1=NCCN1</smiles>

\section{- $\mathrm{HCl}$}

Figure 1: Chemical structure of Oxymetazoline hydrochloride

Oxymetazoline hydrochloride occurs as a white, almost odorless, crystalline powder. It has a molecular weight of $260.38 \mathrm{~g} / \mathrm{mol}$. It has a melting point of about $182{ }^{\circ} \mathrm{C}$. It is freely soluble in water and methanol 7 .

In present, official method for quantification of Oxymetazoline hydrochloride is available and that is of titrimetric method 8 , which is time consuming and highly sensitive, but simple, accurate and precise reverse phase HPLC method is not available. Our interest of work was to develop suitable HPLC method required for analysis and characterization of Oxymetazoline hydrochloride from nasal spray formulation.

\section{MATERIALS AND METHODS}

\subsection{Materials and Reagents}

Oxymetazoline hydrochloride working standard and Placebo were a kind gift of Shalini Chemicals, Aurangabad, Maharashtra. Test samples purchased from market store. HPLC grade Acetonitrile, Potassium dihydrogen phosphate and HPLC Water were purchased from Ranbaxy Fine Chemicals Ltd., India.

\subsection{HPLC system}

High-performance liquid chromatographic system (Agilent (1100) Gradient System) equipped with UV-visible detector was used for the analysis. The data were recorded using Chemstation 10.02 software.

\subsection{Preparation of mobile phase}

Dissolved $6.8 \mathrm{gm}$ of $\mathrm{KH}_{2} \mathrm{PO}_{4}$ in to $1000 \mathrm{ml}$ water and sonicated to dissolved ( $\mathrm{pH}$ observed 4.41), adjusted to $\mathrm{pH}$ 3.00 with diluted Orthophosphoric acid solution. Buffer filtered through a $0.45-\mu \mathrm{m}$ PVDF membrane filter and sonicated to degas. Prepared a mixture of Buffer $(\mathrm{pH} 3.0)$ : Acetonitrile (60:40), v/v, sonicated to degas.

\subsection{Preparation of standard solution (40 PPM)}

Accurately weighed and transferred $40 \mathrm{mg}$ of Oxymetazoline hydrochloride working standard in to $100 \mathrm{~mL}$ volumetric flask, added about $30 \mathrm{~mL}$ of Acetonitrile and sonicated to dissolve, wait to cool and diluted up to mark with diluent. Transferred $5 \mathrm{~mL}$ of this solution in to $50 \mathrm{~mL}$ volumetric and diluted up to mark with Mobile Phase.

\subsection{Preparation of sample solution (40 PPM)}

\section{Brand Name:- Naselin Nasal Spray ( CIPLA LTD)}

Transferred $2.0 \mathrm{~mL}$ of Sample solution in to $25 \mathrm{~mL}$ volumetric flask, added about $15 \mathrm{~mL}$ of mobile phase and sonicated to mixed properly, diluted up to mark with mobile phase, and the samples were analyzed using the proposed analytical methods.

\subsection{Preparation of Placebo solution (8 PPM)}

Accurately weighed and transferred $20 \mathrm{mg}$ of Placebo powder in to $200 \mathrm{~mL}$ volumetric flask, added about $100 \mathrm{~mL}$ of mobile phase and sonicated to dissolve, wait to cool and diluted up to mark with mobile phase. Transferred $2 \mathrm{~mL}$ of this solution in to $25 \mathrm{~mL}$ volumetric and diluted up to mark with Mobile Phase.

\subsection{Chromatographic conditions}

The analysis was carried out at temperature $27^{\circ} \mathrm{C}$ under isocratic condition. The mobile phase was run at a flow rate of $1.0 \mathrm{~mL} /$ minute for $10 \mathrm{~min}$. The injection volume was $20 \mu \mathrm{L}$ for blank, placebo, standard and sample solution . Before analysis, every standard and sample were filtered through $0.45 \mu \mathrm{m}$ Nylon syringe filter. The analysis was monitored with UV detection at $203 \mathrm{~nm}$.

\subsection{Method validation}

Method validation is the process used to confirm that the analytical procedure employed for a specific test is suitable for its intended use. Results from method validation can be used to judge the consistency, quality and reliability of analytical results; it is an integral part of any good analytical practice. Typical parameters verified in validation of analytical method are listed in table 1 . ICH Q2(R1) ${ }^{9}$ is considered the primary reference for recommendations and definitions on validation characteristics for analytical procedures.

Table 1: Typical parameters verified in method validation

\begin{tabular}{|l|l|}
\hline Sr No & Validation parameter \\
\hline 1 & System suitability \\
\hline 2 & Specificity \\
\hline 3 & Precision \\
\hline 4 & Accuracy \\
\hline 5 & Linearity \\
\hline 6 & Robustness \\
\hline
\end{tabular}

\subsubsection{System suitability}

System suitability is an essential parameter of any analytical method development. The tests are based upon the concept that the equipment, electronics, analytical operations and samples to be analyzed constitute an integral system that can be evaluated as such. System suitability test ensure adequate performance of the chromatographic system and quality of the method for accurate results. It is required to done before every sample analysis. To determine system suitability Oxymetazoline Hydrochloride standard solution was prepared and injected for six times into HPLC system. The mean, SD and \% RSD for peak areas of Oxymetazoline was calculated.

\subsubsection{Specificity}

Assuring specificity is the first step in developing and validating a good analytical method ${ }^{10}$. Specificity ensures the identity of the analyte of interest. The ICH documents define specificity as the ability to measure accurately and specifically the analyte of interest in the presence of other components that may be expected to be present in the sample matrix such as impurities and degradation products. The placebo solution containing excipients without 
Oxymetazoline were injected. To evaluate the specificity of the method blank, placebo and sample solution were injected.

\subsubsection{Precision}

Precision is the degree of agreement among individual test results when an analytical method is used repeatedly to multiple samplings of a homogeneous sample. The precision of an analytical procedure is usually expressed as the standard deviation or relative standard deviation (coefficient of variation) of a series of measurements. Precision may be a measure of either the degree of reproducibility or of repeatability of the analytical procedure under normal operating conditions. The precision of the assay method was assessed with respect to repeatability and reproducibility. Repeatability is also termed intra-assay precision. Sample of a single batch were prepared six times and analyzed as per test method, \% assay of Oxymetazoline for six samples calculated for method precision.

\subsubsection{Accuracy}

The accuracy of an analytical procedure is the closeness of test results obtained by that procedure to the true value. The accuracy of an analytical procedure should be established across its range. Accuracy should be reported as percent recovery by the assay of known added amount of analyte in test solution. In this study, successive analysis $(n=3)$ for three different concentrations of standard mixtures $(80,100$ and $120 \%)$ was carried out to determine the accuracy of proposed method.

\subsubsection{Linearity}

The linearity of an analytical procedure is its ability within a given range to obtain test results which are directly proportional to the concentration (amount) of analyte in the sample. Linearity has been performed on different concentrations within $25-150 \%$ of the nominal standard concentration. The linearity of this proposed method was evaluated by using calibration curve to calculate the coefficient of correlation, slope, and intercept values.

\subsubsection{Robustness}

Robustness is a capacity of the method to remain unaffected by small deliberate, variations in method parameters. Robustness is an indication of the reliability of the analytical method during normal usage. The effect of the following deliberate changes in chromatographic conditions was monitored: Detector wavelength $\pm 2 \mathrm{~nm}$, Flow rate $\pm 10 \%$, Temperature $\pm 2{ }^{\circ} \mathrm{C}$, and $\mathrm{pH}$ of Buffer solution \pm 0.1 .

\section{RESULTS AND DISCUSSION}

\subsection{System suitability}

The results of system suitability observed within acceptable limits as shown in table 2 .

Table 2: Results from the determination of system precision

\begin{tabular}{|c|c|}
\hline Standard No & Peak area of Oxymetazoline \\
\hline 1 & 6954 \\
\hline 2 & 6920 \\
\hline 3 & 6998 \\
\hline 4 & 6941 \\
\hline 5 & 6932 \\
\hline 6 & 6943 \\
\hline Mean & $\mathbf{6 9 4 8}$ \\
\hline SD & $\mathbf{2 7 . 0 2}$ \\
\hline \%RSD & $\mathbf{0 . 3 9}$ \\
\hline
\end{tabular}

Values are expressed for six replicate $(n=6)$

Table 3: Data from Method precision

\begin{tabular}{|c|c|}
\hline Sample No & \% Assay of Oxymetazoline \\
\hline 1 & 101.3 \\
\hline 2 & 100.7 \\
\hline 3 & 100.4 \\
\hline 4 & 101.5 \\
\hline 5 & 101.1 \\
\hline 6 & 101.2 \\
\hline Mean & $\mathbf{1 0 1 . 0}$ \\
\hline SD & $\mathbf{0 . 4 2}$ \\
\hline \% RSD & $\mathbf{0 . 4 2}$ \\
\hline
\end{tabular}

Values are expressed as mean \pm standard deviation of six samples $(n=6)$

\subsection{Specificity}

Accuracy should be reported as percent recovery by the assay of known added amount of analyte in the sample 
a)Blank

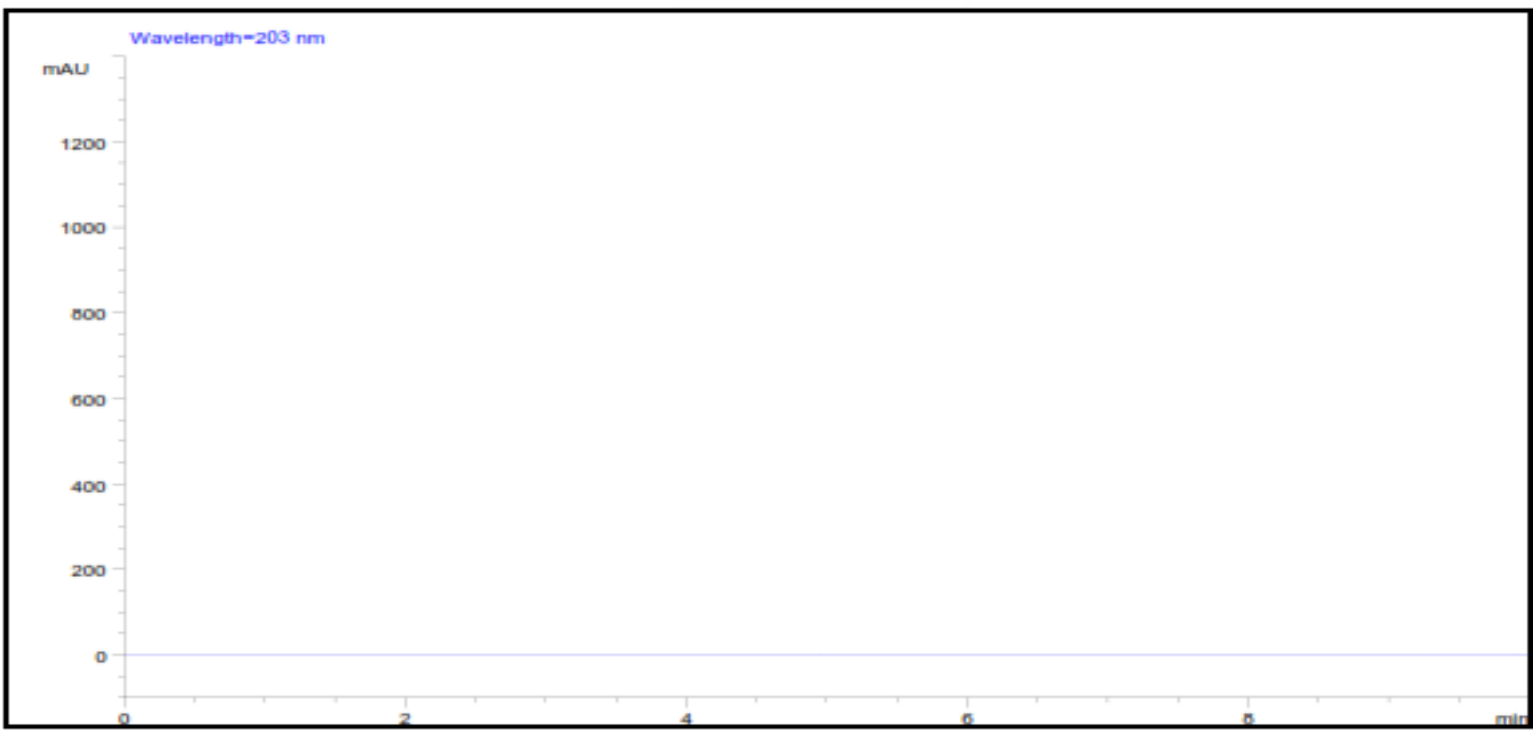

b)Placebo

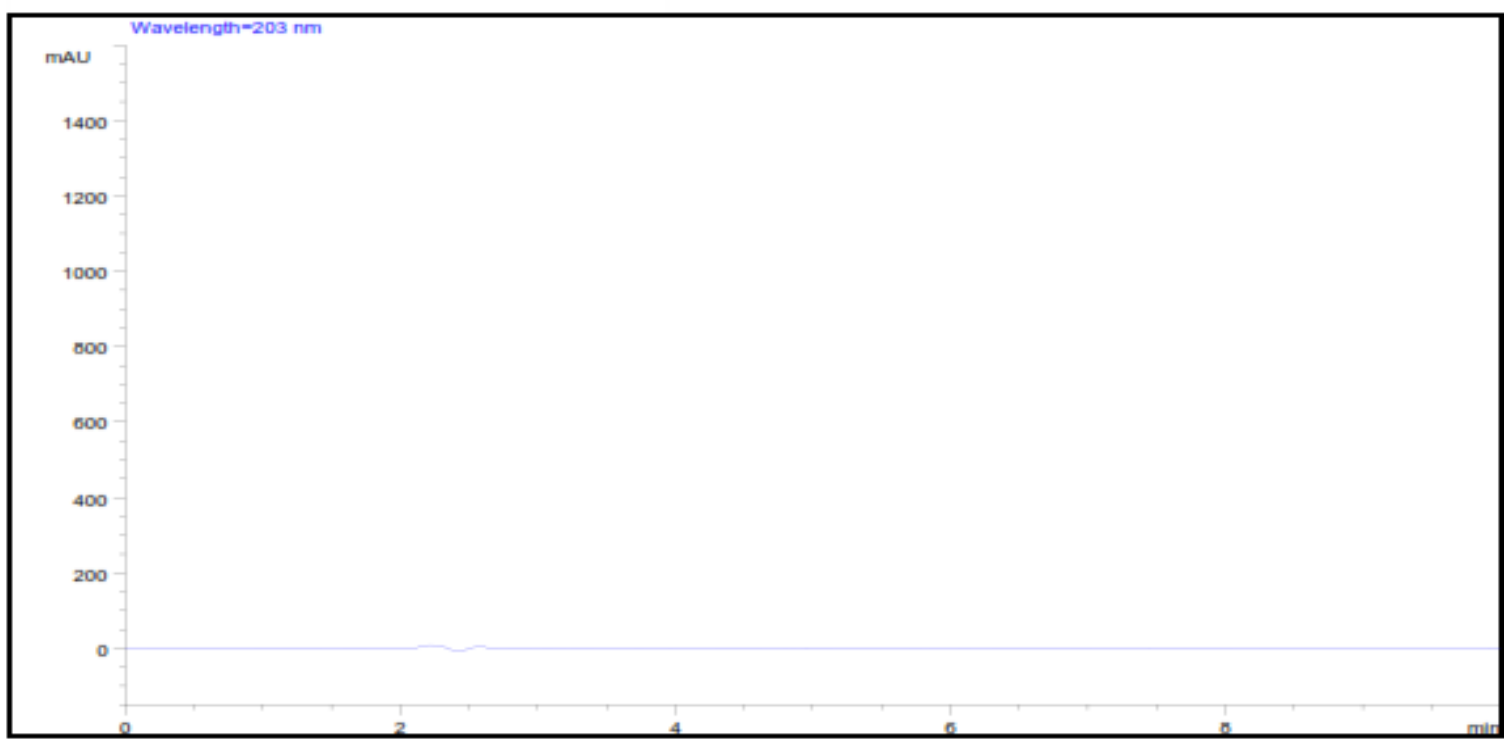

c)Sample solution

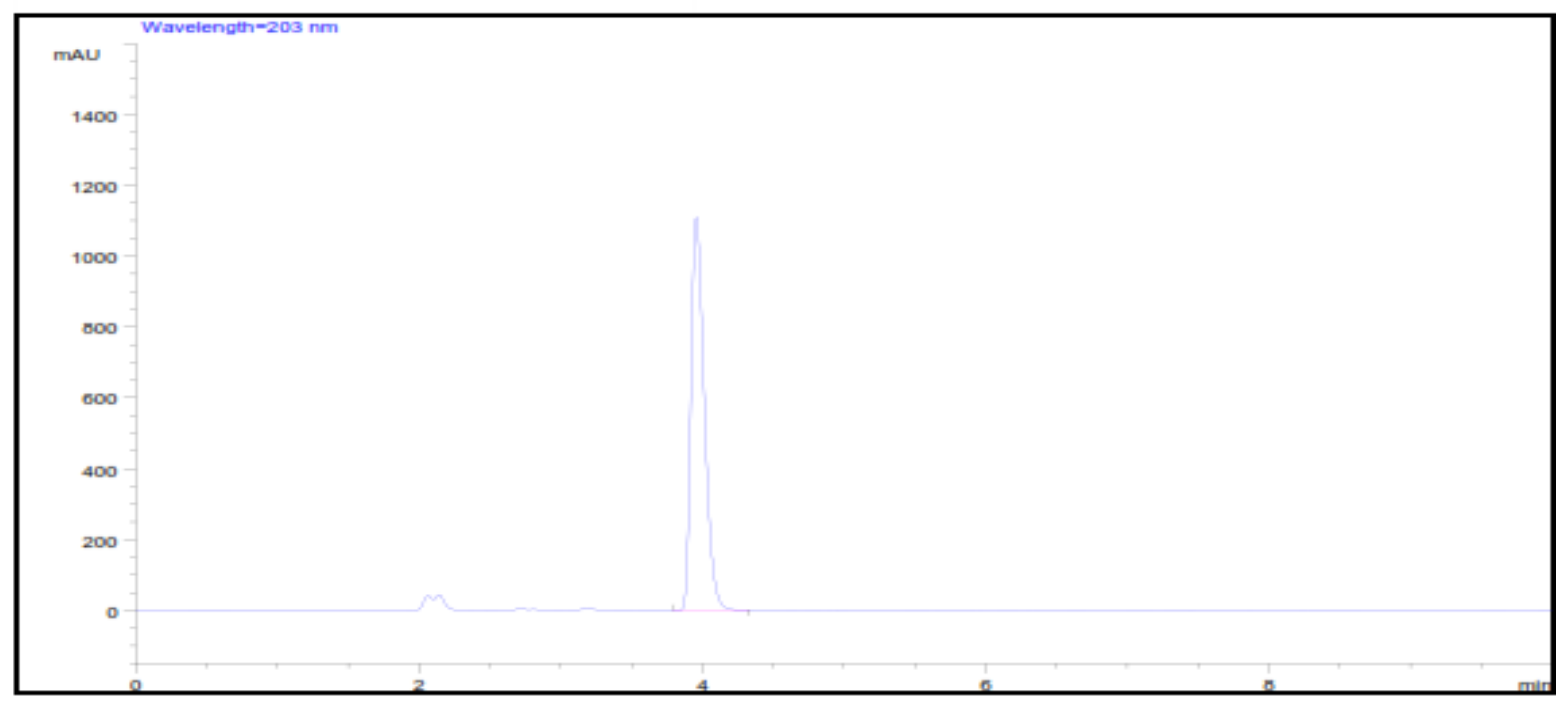

Figure 2: HPLC Chromatogram a)Blank, b)Placebo and c)Sample solution 


\subsection{Accuracy}

Known amount of Oxymetazoline hydrochloride was spiked in placebo at about 80,100 and $120 \%$ of test concentration. The amount of Oxymetazoline hydrochloride recovered was quantified as per developed method. The \% recovery was calculated from the amount found and actual amount added. The results are tabulated in table 4 . The overall recovery of Oxymetazoline hydrochloride in the samples was in between 98.0 to $102.0 \%(\mathrm{RSD}<2 \%)$ which is satisfactory for quantification of Oxymetazoline hydrochloride in nasal spray formulations.

Table 4: Accuracy evaluation of the proposed method for quantification of Oxymetazoline

\begin{tabular}{|c|c|c|c|c|c|c|}
\hline $\begin{array}{c}\text { Spiked level (\%)/ } \\
\text { Sample No }\end{array}$ & $\begin{array}{l}\text { Actual amount of } \\
\text { API added(mg) }\end{array}$ & $\begin{array}{c}\text { Amount of } \\
\text { Oxymetazoline } \\
\text { found (mg) }\end{array}$ & \% Recovery & Mean & SD & $\%$ RSD \\
\hline 80\% Sample-1 & 0.8015 & 0.7907 & 98.6 & \multirow{3}{*}{98.8} & \multirow{3}{*}{0.16} & \multirow{3}{*}{0.16} \\
\hline 80\% Sample-2 & 0.8015 & 0.7926 & 98.9 & & & \\
\hline 80\% Sample-3 & 0.8015 & 0.7931 & 98.9 & & & \\
\hline 100\% Sample-1 & 1.0019 & 0.9974 & 99.6 & \multirow{3}{*}{99.5} & \multirow{3}{*}{0.07} & \multirow{3}{*}{0.07} \\
\hline 100\% Sample-2 & 1.0019 & 0.9966 & 99.5 & & & \\
\hline 100\% Sample-3 & 1.0019 & 0.9962 & 99.4 & & & \\
\hline 120\% Sample-1 & 1.2023 & 1.2092 & 100.6 & \multirow{3}{*}{100.5} & \multirow{3}{*}{0.06} & \multirow{3}{*}{0.06} \\
\hline 120\% Sample-2 & 1.2023 & 1.2086 & 100.5 & & & \\
\hline 120\% Sample-3 & 1.2023 & 1.2079 & 100.5 & & & \\
\hline
\end{tabular}

Values are expressed as mean \pm standard deviation of replicate $(n=3)$

\subsection{Linearity}

A graph was plotted with concentration (in $\mu \mathrm{g} / \mathrm{ml}$ ) of Oxymetazoline hydrochloride on $\mathrm{X}$-axis and peak areas of Oxymetazoline on Y-axis. The results are tabulated in table 5 and graphically represented in figure 3.Excellent linear response has been observed with correlation coefficient $\left(\mathrm{R}^{2}\right)$ values of 0.999 , which was within the limit of the correlation coefficient $\left(\mathrm{R}^{2}=0.995\right)$.

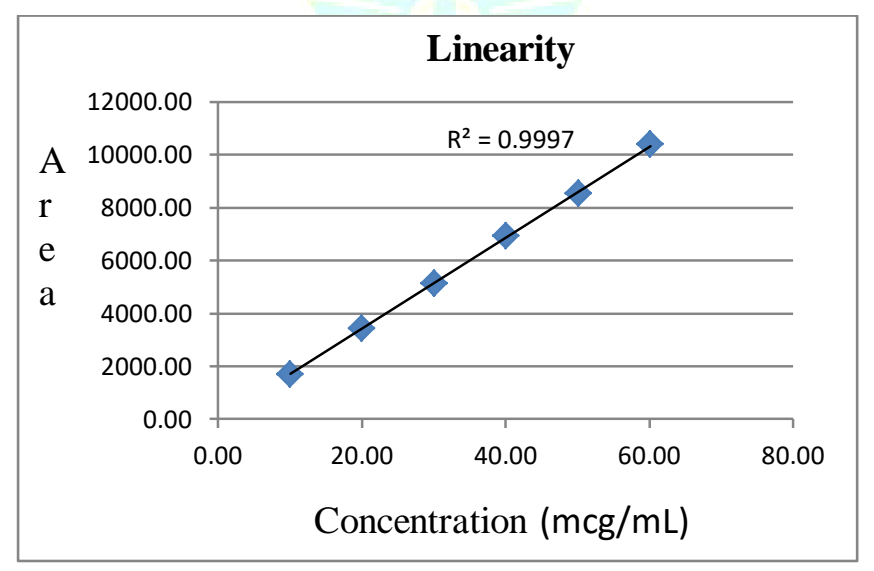

Fig.3: Linearity plot for Oxymetazoline

Table 5: Results of linearity

\begin{tabular}{|c|c|c|}
\hline $\begin{array}{c}\text { Spike level in } \\
\text { \% }\end{array}$ & $\begin{array}{c}\text { Concentration } \\
\text { (mcg/mL) }\end{array}$ & $\begin{array}{c}\text { Average Area } \\
\text { (N=2) }\end{array}$ \\
\hline 25 & 10.03 & 1695 \\
\hline 50 & 20.06 & 3408 \\
\hline 75 & 30.09 & 5112 \\
\hline 100 & 40.12 & 6927 \\
\hline 125 & 50.15 & 8539 \\
\hline 150 & 60.18 & 10399 \\
\hline \multicolumn{2}{|c|}{ Y-Intercept } & -59.47 \\
\hline \multicolumn{2}{|c|}{ Correlation Coefficient ${ }^{\circledR}$} & 0.99989 \\
\hline
\end{tabular}




\subsection{Robustness results}

Robustness of the method was verified by deliberately applying the following chromatographic conditions as shown in table 6 i.e.

I By changing the wavelength by $\pm 2 \mathrm{~nm}$

II By changing the flow rate by $\pm 10 \%$

III By changing the column oven temperature by $\pm 2{ }^{\circ} \mathrm{C}$

IV By changing the $\mathrm{pH}$ of buffer used for mobile phase by \pm 0.1 unit

Table 6: Robustness experiment

\begin{tabular}{|c|c|c|c|c|c|}
\hline $\begin{array}{c}\text { Sr. } \\
\text { No. }\end{array}$ & Robustness Parameter & $\begin{array}{c}\text { Retention Time } \\
\text { (min) }\end{array}$ & $\begin{array}{c}\text { Tailing } \\
\text { factor }\end{array}$ & $\begin{array}{c}\text { Theoretical } \\
\text { plates }\end{array}$ & $\begin{array}{c}\text { \% RSD of Standard } \\
\text { solution }\end{array}$ \\
\hline 1 & Wavelength $201 \mathrm{~nm}$ & 3.77 & 0.96 & 7911 & 0.06 \\
\hline 2 & Wavelength $205 \mathrm{~nm}$ & 3.78 & 0.96 & 7904 & 0.08 \\
\hline 3 & Flow rate $(0.90 \mathrm{~mL} / \mathrm{min})$ & 4.18 & 0.86 & 9321 & 0.12 \\
\hline 4 & Flow rate $(1.10 \mathrm{~mL} / \mathrm{min})$ & 3.59 & 0.88 & 8831 & 0.07 \\
\hline 5 & Column Temp 25 ${ }^{\circ} \mathrm{C}$ & 4.00 & 0.89 & 7869 & 0.04 \\
\hline 6 & Column Temp 29 C & 4.00 & 0.89 & 7854 & 0.09 \\
\hline 7 & Buffer $\mathrm{pH} 2.9$ & 4.01 & 0.91 & 7452 & 0.05 \\
\hline 8 & Buffer $\mathrm{pH} 3.1$ & 4.03 & 0.89 & 7519 & 0.11 \\
\hline
\end{tabular}

\subsection{Estimation of formulations}

The observation for assay of Oxymetazoline hydrochloride in nasal spray formulations ranged from $100.4 \%$ to $101.5 \%$ with a standard deviation of not more than $0.42 \%$. The assays for the formulations were observed same as mentioned in the label claim, indicating that the suitability of the proposed analytical method. The estimated drug content with low values of standard deviation established the precision of the proposed method.

\subsection{DISCUSSION}

Development of an analytical method for assessment of drugs in the pharmaceutical dosage form is of most necessity to confirm the quality of nasal formulations with respect to assay and spray content uniformity.

Development and validation of Oxymetazoline hydrochloride by high performance liquid chromatography is reported in literature ${ }^{11,12}$ but we have observed below drawbacks in hose analytical methods which are as follows:

- Almost all methods are time consuming which affects on productivity in routine sample analysis.

- Usage of organic solvent more than $45 \%$ is not at all cost effective and also affects on chromatographic conditions; buffer salts may precipitate

- Complex methodology effects on accuracy of analytical method and man power utilization in pharmaceutical industry.

Our developed HPLC analytical method for estimation of Oxymetazoline in nasal spray formulations has used minimum amount of organic solvents which is cost effective, economic and environment friendly. The wavelength used in proposed analysis method also efficient to trace unexpected solvent peaks qualitatively.

\subsection{CONCLUSIONS}

A very simple reversed-phase HPLC method for the routine and stability analysis of Oxymetazoline hydrochloride in nasal spray formulations was developed and validated. The proposed method is new, simple, accurate, precise, robust, specific and linear over the analysis ranges and also able to resolve the drug from excipients in a short analytical run time.

\section{ACKNOWLEDGMENT}

We thank Mr Anil Vispute, Shree Industrial Training Centre And Research Laboratory, Jalgaon, Maharashtra for providing required laboratory facilities and $\mathrm{Mr}$ Dhananjay Ghagare, Senior Research Scientist, Wockhardt Research center, Aurangabad for providing support and enthusiasm to complete this work.

\section{CONFLICT OF INTERESTS}

\section{Declared none}

\section{REFERENCES}

1.https://www.drugoffice.gov.hk/eps/do/en/consumer/news_infor mations/dm_15.html\#b

2.https://en.wikipedia.org/wiki/Allergic_rhinitis

3. https://en.wikipedia.org/wiki/Category:Antiasthmatic_drugs

4.https://www.nationalasthma.org.au/living-withasthma/resources/patients-carers/brochures/hay-feverallergic-rhinitis-and-your-asthma

5.https://www.ncbi.nlm.nih.gov/pubmed/21377716

6.https://en.wikipedia.org/wiki/Oxymetazoline

7.https://pubchem.ncbi.nlm.nih.gov/compound/oxymetazoline\#sec tion=Chemical-and-Physical-Properties

8.European Pharmacopoeia 8.0:2944

9.ICH Harmonized Tripartite Guideline Validation of Analytical Procedures: Text And Methodology Q2(R1); 1996.

10.Lloyd R. Snyder, Joseph J. Kirkland, Joseph L. Glajch. Practical HPLC method development, second edition, p.696

11.Beata Stanisz and Wojciech Nowinski. Determination of Oxymetazoline hydrochloride and decomposition products by high performance liquid chromatography. Acta poloniae Pharmaceutica-Drug research. Vol-57 No. 6 pp. 399-401, 2000

12. T.J.Hoffman, R.D.Thompson and J.R.Seifert. Determination of the Nasal Decongestant, Oxymetazoline Hydrochloride, in Pharmaceutical Formulations by Hplc. Drug Development and Industrial Pharmacy, Volume 15, 1989, Issue 5. 